\title{
A BIBLIOMETRIC ANALYSIS OF NATURAL DISASTERS AND BUSINESS MANAGEMENT IN TOURISM
}

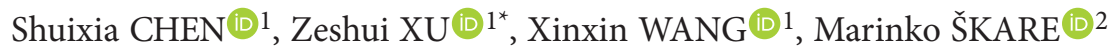 \\ ${ }^{1}$ Business School, Sichuan University, Chengdu, China \\ ${ }^{2}$ Faculty of Economics and Tourism "Dr Mijo Mirkovic", Juraj Dobrila University of Pula, \\ Preradoviceva 1-1, 52100 Pula, Croatia
}

Received 20 July 2020; accepted 29 October 2021

\begin{abstract}
Natural disasters are a critical factor for the development of business management in the tourism industry, leading to an increasing number of publications on the relationship between natural disasters and tourism business management (ND\&T). In order to identify the research status of ND\&T and explore the direction for future research, this paper collects 335 publications related to ND\&T and develops a bibliometric analysis of the existing publications. First, we map the leading countries/regions, institutions, authors, and journals of ND\&T to visualize the general analysis. Then the cooperation network is provided to show the collaboration relationship between countries/regions, institutions, and authors. Third, we introduce the keyword analysis to obtain research hotspots of ND\&T. And finally, we explore the research theme analysis through literature review and conclude four topics. The findings of the topic analysis suggest that research on ND\&T is receiving increasing attention, and more cooperation is required in the future to deepen the theoretical and empirical focus on tourists.
\end{abstract}

Keywords: natural disasters, tourism business management, bibliometric analysis, cooperation network analysis, keywords analysis, literature review, Web of Science.

JEL Classification: Z32, L83.

\section{Introduction}

The frequent occurrences of natural disasters have caused numerous fatalities and economic tolls (Zhou et al., 2018). Earthquakes, floods, epidemics, and other natural disasters have disastrous impacts on human life, disrupting normal socio-economic activities. For instance, the 2004 Indian Ocean Earthquake generated a catastrophic tsunami, leaving more than 226,000 people dead or missing (Rabinovich et al., 2006). In 2020, tens of millions of people had been infected by the coronavirus disease (COVID-19), and the economic development of most countries in the world remains in the doldrums (Verma \& Gustafsson, 2020).

*Corresponding author. E-mail: xuzeshui@263.net

Copyright (c) 2022 The Author(s). Published by Vilnius Gediminas Technical University

This is an Open Access article distributed under the terms of the Creative Commons Attribution License (http://creativecommons. org/licenses/by/4.0/), which permits unrestricted use, distribution, and reproduction in any medium, provided the original author and source are credited. 
Throughout the history of humankind, natural disasters are caused by natural changes and human factors. No matter the causes, once happened, the impact of natural disasters on human production and business activities is immeasurable.

Compared to other industries, tourism is more vulnerable to natural disasters as its heavy dependence on natural resources. The damages caused by natural disasters often destroy tourism destinations, tourism traffic, and individual tourism intention (Stylidis et al., 2014), thereby resulting in massive shocks on tourism business management. For example, the 2016 Kumamoto earthquake led to a massive drop in visitor numbers, with about 2.3 million fewer than the same period last year. Additionally, the tourism industry is highly dependent on the natural environment and weather, and extreme weather may lead to natural disasters for 1.8 billion international tourists in 2030 (Tsai et al., 2016). The continuing impact of natural disasters on business management in the tourism industry has also brought significant attention on research opportunities in the field of natural disasters and tourism business management (ND\&T). Many academics and practitioners are focusing on understanding the relationships between ND\&T, thereby reducing the negative impact of natural disasters on tourism business management. As a result, the academic research related to ND\&T has flourished and the number of research publications has grown rapidly. Research topics range from the negative impact of natural disasters, countermeasures of tourism business management, post-disaster recovery methods, etc. Hence, it is valuable to provide the overview of the existing ND\&T publications to the interested scholars to help them understand the research profile so far.

To help academics and practitioners understand the research profile of ND\&T, we wish to clarify the research status of ND\&T and explore the direction of future research. In this regard, this paper proposes a bibliometric analysis to examine the existing research publications related to ND\&T. Bibliometric analysis is a quantitative method that can be used to analyze the research status of the target research field (X. X. Wang et al., 2021a). Numerous researchers have adopted bibliometric analysis to understand the development of journals (Yu et al., 2017), research directions (Rodríguez-López et al., 2020). While compared to bibliometric analysis related to sustainable tourism (Moyle et al., 2021) and intelligent tourism (Johnson \& Samakovlis, 2019), less progress has been made in the bibliometric analysis of ND\&T. A few studies have focused on the bibliometric visualization of tourism crisis and disaster management (Jiang et al., 2019). However, bibliometric analysis that considers the inner structure and evolution of ND\&T is still in its infancy. To fill the research gap, this study aims to develop a bibliometric analysis of ND\&T literature, and therefore make it more accessible to researchers. This paper focuses on the following main research issues:

RQ1. What are the general developments of publications in the field of ND\&T?

RQ2. What are the cooperation relationships of the existing researches on ND\&T?

RQ3. What are the main topics of the current research within ND\&T?

RQ4: What are the possible future research directions of ND\&T?

The remaining of this paper is organized as followed: The methodology is introduced in Section 1. Section 2 gives the results of this paper, including general analysis, cooperation networks, and keywords analysis. Findings and discussions of the literature review are shown in Section 3. Furthermore, we conclude this paper in the final section. 


\section{Methodology}

The objective of the bibliometric analysis is to provide a structured overview of the existing publication databases. Moreover, the publication source database, publication analysis method, and statistical software are three critical contents. Therefore, the methodology of this paper uses these three aspects, and the framework is shown in Figure 1.

First, as for the publication database, commonly used sources include Web of Science (WoS), Scopus, Google Scholar. Among these database sources, WoS is one of the most widely used ones as there are amounts of high-quality journals and publication information in this database. In this paper, we choose the WoS core collection to collect publications related to ND\&T to ensure a broader range of leading journals compared to Google Scholars or others. After determining the database, we input the keywords "natural disaster" and "tourism" to collect publications. In the search query, "business management" is not included because many papers do not include the term but do discuss ND\&T in terms of "impact", "planning", etc. To obtain as many relevant publications as possible, we extend the two keywords to related synonyms for data collection. Keywords regarding natural disasters include natural disasters, natural hazards, and natural calamities. Furthermore, search keywords related to tourism research are tourism, travel, tourist, visit, hospitality, hotel, and destination. We combine the search scenarios using the title, abstract, and keywords: (tourism OR travel OR tourist OR visit OR hospitality OR hotel OR destination) AND ("natural disaster*” OR "natural hazard*" OR "natural calamities").

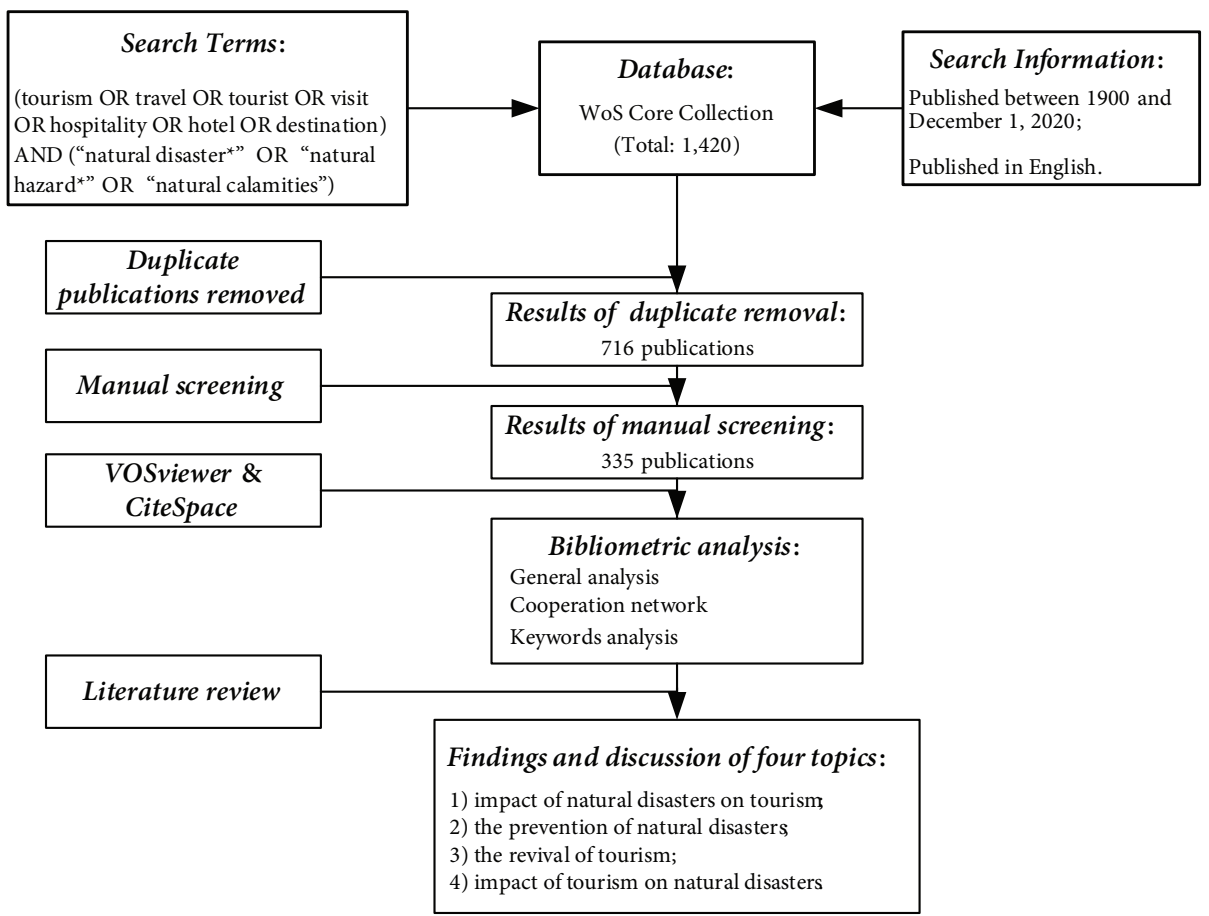

Figure 1. Methodology framework of this paper 
The publication data collection finished on December 1, 2020. In order to make the data complete, we search the publications from the earliest time of WoS, i.e., 1900. Only publications in English are considered during collection. After defining the search information, we obtain 1,420 publications with information like keywords, citation, source. Then, we compare the collected publications and delete duplicate publications to obtain 716 publications. Next, we manually screen the 716 publications, delete some irrelevant ones, and finally obtain 335 publications. After data filtering, we can obtain that the first paper in the 335 publications was published in 1992, written by some authors from China. That is, we finally collect 335 publications with the timespan from 1992 to 2020.

Second, in terms of publication analysis method, most bibliometric methods apply to different scales of analysis, ranging from micro (authors) to meso (countries/regions and journals) to macro (whole fields). Inspired by the existing bibliometric methods, this paper first analyzes the existing research's annual publications and main research directions. Then, we analyze prolific and influential publication sources, including countries/regions, institutions, authors, and journals. The above process is called general analysis in this paper, and then we discuss the cooperation network to discover collaboration relationships between countries/ regions, institutions, and authors. The collaboration network is obtained by the co-authorship analysis based on the social network. The items in the collaboration network, including countries/regions, institutions, and authors, are related to each other through the co-authored publications. The obtained network can well illustare the structural features of the target research topic (X. X. Wang et al., 2021b). Finally, keywords analysis, including keywords co-occurrence, burst detection, and timeline view analysis, is introduced to obtain research hotspots of ND\&T. The co-occurrence analysis is a commonly used content analysis method in bibliometric analysis. This method records the occurrence of the two keywords together among the publications, which is helpful to reveal the conceptual structure of the research area. Different from the co-occurrence analysis of keywords, the burst detection analysis aims to detect the emerging trends of publications within a certain time period. By combining the number of citations, the results of burst detection can help to identify the emerging trends of keywords, authors, and references. Additionally, the timeline analysis aims to reveal the dynamic features over the time slice, including the potentially transformative changes and emerging trends. And this method can well present the developing tendency of keywords and the hot topics or research directions. In addition to the mentioned bibliometric methods, we also present the literature review of ND\&T to explore further the main topics of the existing research find four topics, as shown in Figure 1.

Finally, some statistical software packages can be adopted to achieve the above bibliometric analysis. Considering that no single tool can provide a comprehensive bibliometric analysis (Cobo et al., 2014), this paper adopts VOSviewer and CiteSpace to conduct the scientific cartographic analysis of ND\&T-related publications. The VOSviewer is employed to present the general trend of researches, including general analysis and the cooperation network analysis. At the same time, the evolution trends of themes in the research field can be well illustrated by CiteSpace. 


\section{Results}

This section introduces the results of bibliometric analysis, including general analysis, cooperation network, and keywords analysis. In the following analysis, all words have been processed to ensure their integrity, including synonym substitution (e.g., tourism and travel), singular and plural substitution (e.g., disaster and disasters), and abbreviation substitution (e.g., the University of Queensland and Univ Queensland).

\subsection{General analysis}

In this section, the general analysis of ND\&T follows the research paradigm from macro (i.e., annual publications and main research directions) to meso and micro (i.e., prolific and influential publication sources).

\subsubsection{Annual publications and main research directions}

This subsection analyzes the annual publications and main research directions to discover the fundamental characteristics of the existing publications. The annual publication of ND\&T from 1992 to 2020 is shown in Figure 2. The publications on ND\&T show an upward trend year by year, except for 2013, 2014, and 2017. The increasing of publications reveals the changes of external environments, and it can be therefore obtained that the focuses on ND\&T are increasing year by year.

After obtaining the annual publications of ND\&T, this paper visualizes the main research directions to reveal the research interests of ND\&T. According to the WoS database, the collected publications cover 29 research directions. The top 10 research directions are shown in Figure 3. We find that the research directions of the existing publications are widely distributed, ranging from social sciences to natural sciences. This phenomenon indicates that ND\&T has attracted the attention of scholars in many fields and can be analyzed from many perspectives like environmental sciences, ecology, business economic, and others.

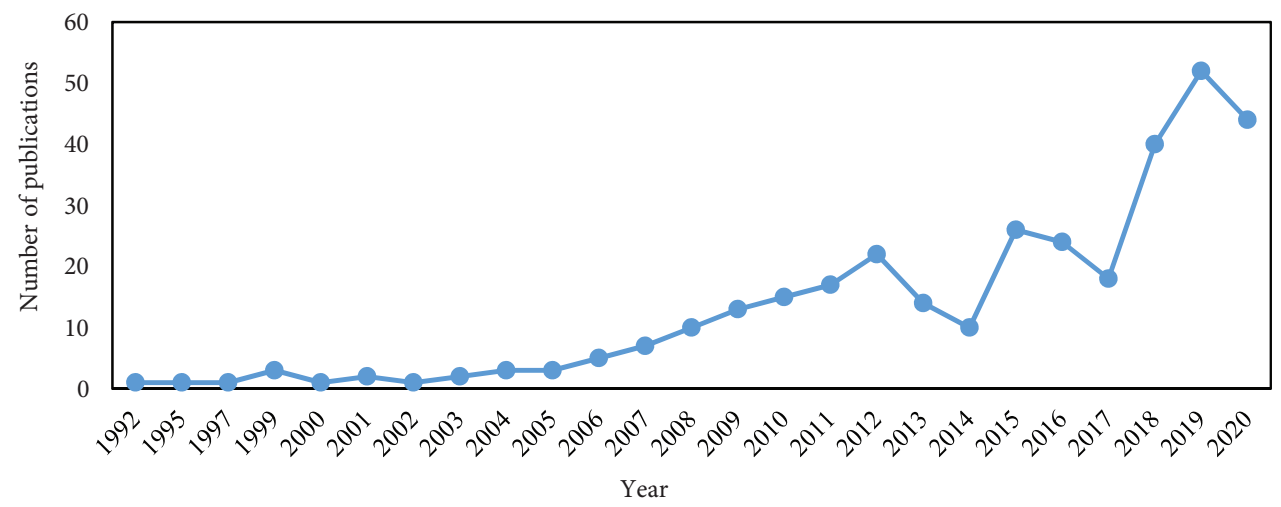

Figure 2. Annual publication from 1992 to 2020 


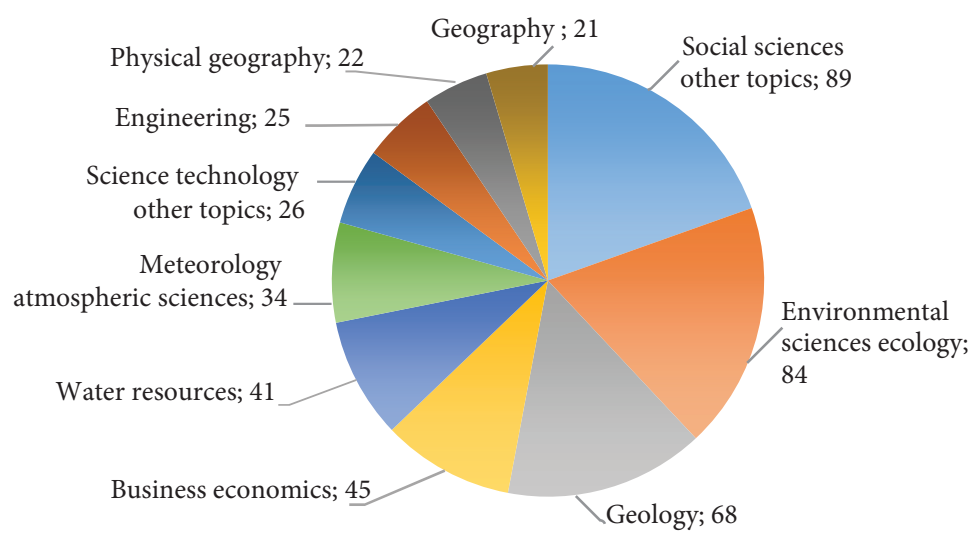

Figure 3. The top 10 research directions of the publications related to ND\&T

After understanding the fundamental characteristics of the existing publications, we then select some prolific and influential publication sources to analyze ND\&T publications.

\subsubsection{Prolific and influential publication sources}

This subsection analyzes the prolific and influential publication sources to reveal the research status of ND\&T. The prolific and influential publication sources defined in this paper include countries/regions, institutions, authors, and journals with a large number of publications. In this paper, some commonly used indicators are selected to qualify the influence of publication sources, including the total number of publications (TP) and the total number of citations (TC). TP and TC of the top 10 prolific countries/regions, institutions, authors, and journals are shown in Table 1 and Table 2, respectively.

In terms of countries/regions, the collected 335 publications cover 73 countries/regions. Furthermore, as shown in Table 1, 268 publications belong to the top 10 countries/regions, with nearly $80 \%$. This result indicates that most publications are generated by prolific countries/regions. Among these prolific countries/regions, the USA is the most prolific country/ region. Therefore, the ranking of TC in Table 2 is not entirely consistent with the ranking of TP.

Nevertheless, on the whole, countries/regions with higher TP also have higher TC. Since a publication may be associated with many institutions, 569 institutions have published papers related to ND\&T. As for TC of ND\&T-related publications, there are over 6,000 institutions that have citation relationships with publications related to ND\&T. As for the authors, 1,018 authors have participated in the research field. Moreover, it can be found that, unlike other research areas where there are scholars who have made outstanding contributions, the authors' distribution in the field of ND\&T is relatively average. Furthermore, the top 10 prolific journals can be divided into three types of journals: (1) cross-disciplinary, such as Sustainability; (2) disaster-related like Natural hazards, and (3) tourism-related like Current issues in tourism. Scholars who have interests in ND\&T can follow these journals to focus on the existing research and future potential research directions. 


\begin{tabular}{|c|c|c|c|c|c|c|c|c|c|c|}
\hline$\stackrel{2}{\stackrel{2}{*}}$ & $\stackrel{m}{2}$ & $\stackrel{m}{=}$ & $\cong$ & $=$ & $a$ & $\infty$ & $\wedge$ & 0 & 0 & in \\
\hline 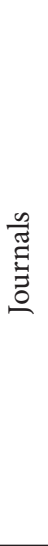 & 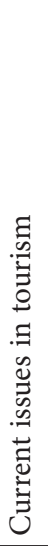 & 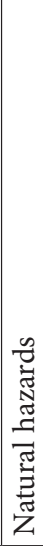 & 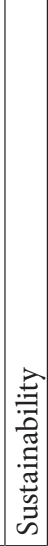 & 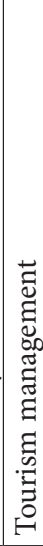 & 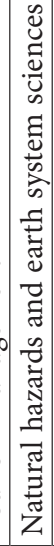 & 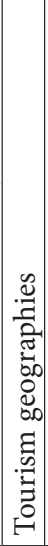 & 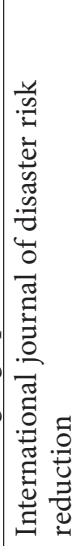 & 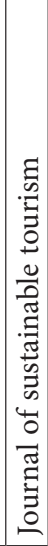 & 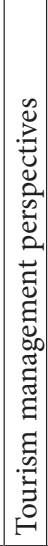 & 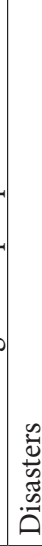 \\
\hline 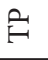 & $\infty$ & 6 & in & in & 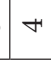 & $\theta$ & $r$ & $m$ & $n$ & $m$ \\
\hline 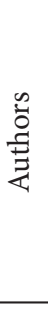 & 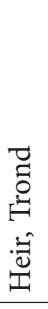 & 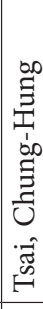 & 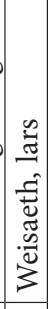 & 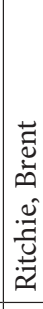 & 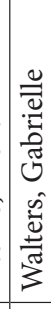 & 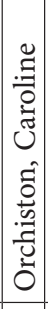 & 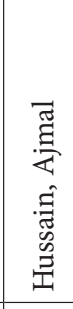 & 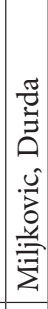 & 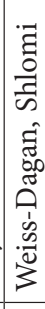 & 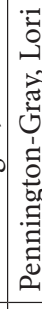 \\
\hline$\stackrel{\nexists}{F}$ & 으 & 으 & $\stackrel{0}{1}$ & 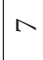 & $\wedge$ & 6 & 6 & in & in & in \\
\hline
\end{tabular}

泀

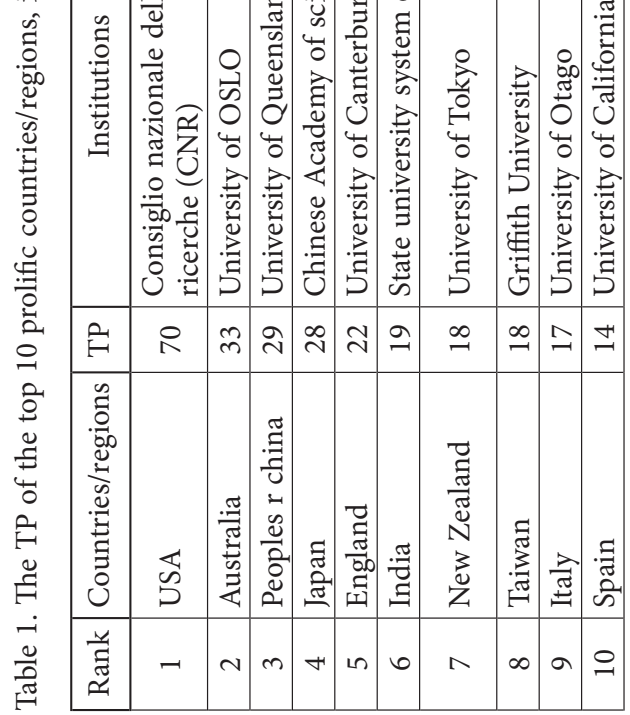

\begin{tabular}{|c|c|c|c|c|c|c|c|c|c|c|}
\hline$\stackrel{U}{U}$ & $\curvearrowright$ & กิ & $\stackrel{-}{\circ}$ & $\infty$ & $\Re$ & $\ddot{\sim}$ & $\stackrel{\circ}{\wedge}$ & in & $\stackrel{\infty}{\sim}$ & $\Xi$ \\
\hline 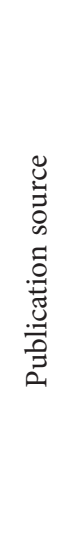 & 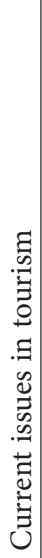 & 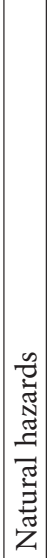 & 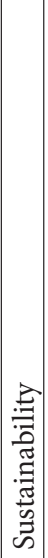 & 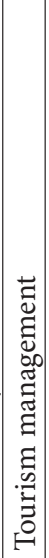 & 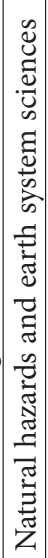 & 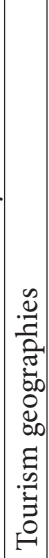 & 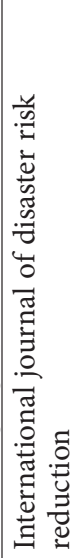 & 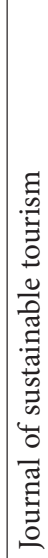 & 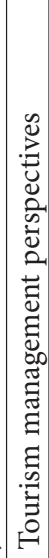 & 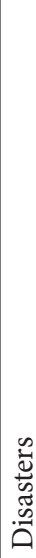 \\
\hline$\underset{H}{U}$ & F & 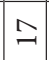 & 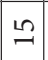 & $\hat{m}$ & $\simeq$ & 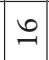 & $\stackrel{0}{0}$ & $m$ & 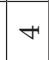 & ऽ \\
\hline 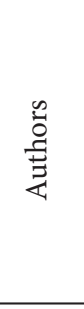 & 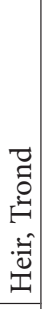 & 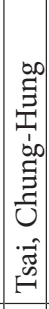 & 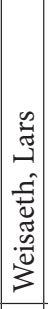 & 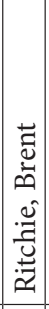 & 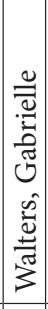 & 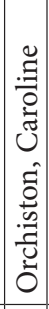 & 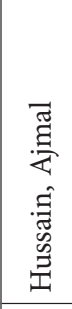 & 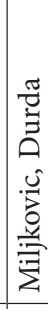 & 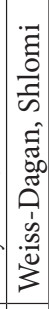 & 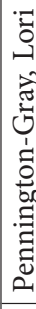 \\
\hline$\underset{H}{U}$ & ฉ̊ & $\hat{\sigma}$ & $\Xi$ & in & $\stackrel{+}{\circ}$ & $\vec{\infty}$ & $m$ & ন & $\vec{\lambda}$ & 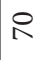 \\
\hline 泀 & 兄 & 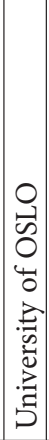 & 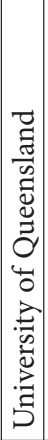 & 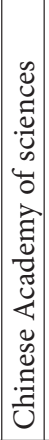 & 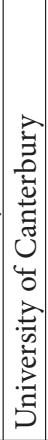 & 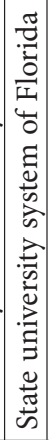 & 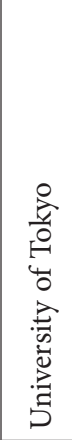 & 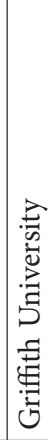 & 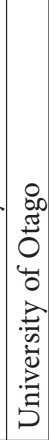 & 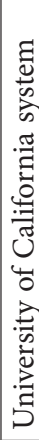 \\
\hline$\underset{H}{U}$ & $\bar{\sigma}$ & $\frac{10}{m}$ & $\vec{L}$ & $\hat{m}$ & 足 & $\stackrel{\sim}{\sim}$ & $\triangle$ & 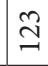 & $\underset{\sim}{\tilde{N}}$ & $\hat{\sigma}$ \\
\hline 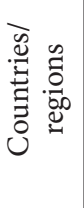 & $\begin{array}{l}\widetilde{\omega} \\
:\end{array}$ & 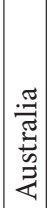 & 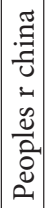 & 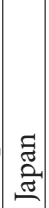 & 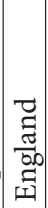 & $\frac{\tilde{g}}{\tilde{Z}}$ & $\begin{array}{l}\vec{Z} \\
\text { J } \\
\vec{J} \\
N \\
3 \\
3 \\
z\end{array}$ & 㿣 & 预 & $\begin{array}{l}\text { : } \\
\text { कै }\end{array}$ \\
\hline 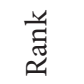 & $\neg$ & $\sim$ & $m$ & + & in & 6 & $\wedge$ & $\infty$ & $a$ & $ㅇ$ \\
\hline
\end{tabular}




\subsection{Cooperation network}

The subsection discusses the cooperation network of these publications. The cooperative network analysis is constructed from countries/regions, institutions, and authors.

\subsubsection{Country/region collaboration network}

The country/region collaboration network can be obtained by VOSviewer, as shown in Figure 4. Figure 4 shows the most extensive connection items in 72 countries/regions (62 countries/regions included) to illustrate the results better. The size of the node in this figure represents the publication number of the country/region. The connected countries/regions by link indicate that there is a cooperative relationship between them. The nodes of different colors represent different clusters. All the parameters and collaboration networks below have the same meaning.

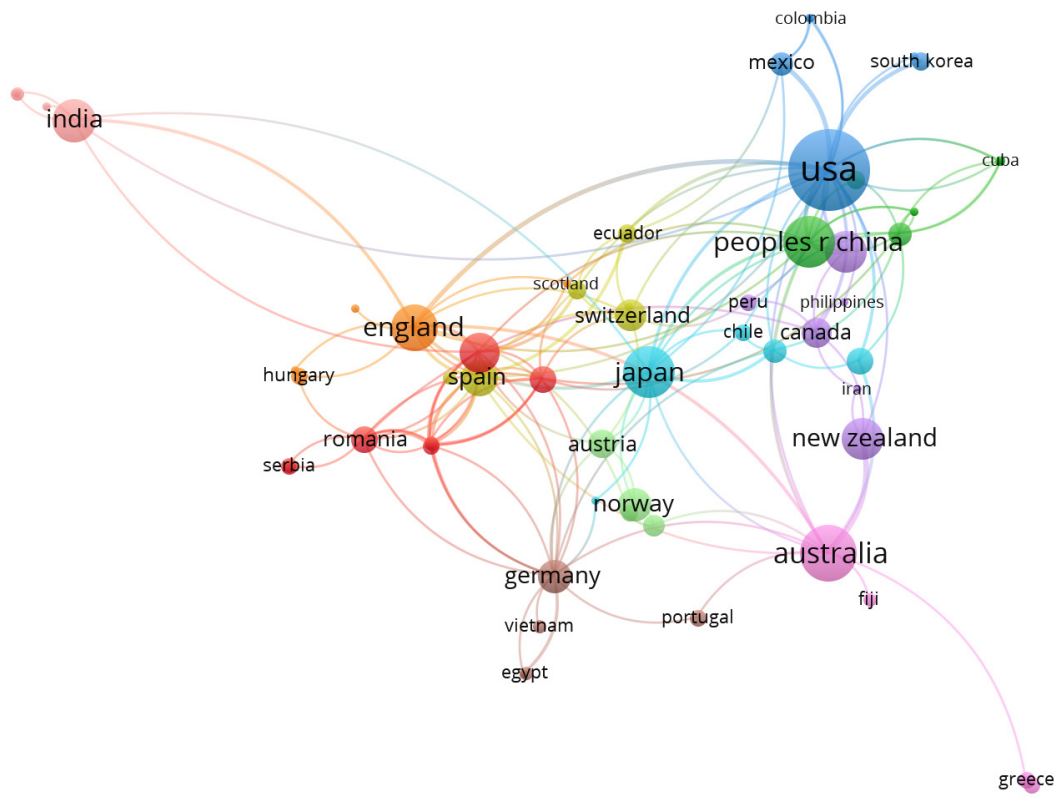

Figure 4. Country/Region collaboration network

In Figure 4, the selected 62 countries/regions are divided into 11 clusters, in which the USA is the most cooperative one. Further analysis on country/region collaboration networks indicates that countries/regions belonging to the same cluster are widely distributed in different continents. These results indicate that the cooperation between countries/ regions is not entirely geographically distributed. Moreover, cross-regional collaboration is an inexorably trend. The top 10 prolific countries/regions fall into 9 clusters. Specifically, except New Zealand and Taiwan belong to the same cluster, other countries/regions belong to different clusters, indicating that these prolific countries/regions are not cooperating very closely. 


\subsubsection{Institution collaboration network}

Institution collaboration networks can present the relationships of institutions. In this subsection, the institution collaboration network is constructed by VOSviewer and shown in Figure 5. In this figure, we adopt two subgraphs to show the collaboration network clearly. The left subgraph represents the overall collaboration network, and the right subgraph represents the maximum subnetwork of the institution collaboration. In the overall cooperation network, there are 511 institutions and 342 clusters. As can be seen from a series of discrete points in this network, the cooperation of most institutions is limited. In other words, these institutions only cooperate with others within a specific scope and have no contact with institutions outside the scope. The maximum subnetwork in Figure 5 illustrates the inner relationship of collaboration institutions.

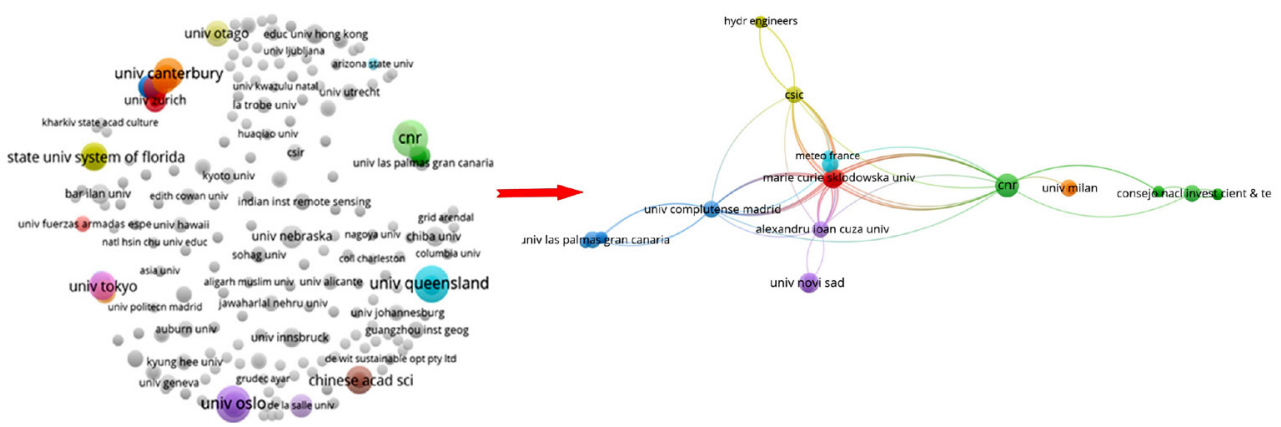

Figure 5. Institution collaboration network and maximum subnetwork

From Figure 5, it can be found that CNR, the University of California system, and the University of OSLO are more collaborative and cooperate more closely with other institutions. Furthermore, in terms of a cluster, the top 10 institutions are divided into 9 clusters, indicating that these institutions do not cooperate very closely.

\subsubsection{Author collaboration network}

This subsection introduces the author's collaboration network to illustrate the relationships of authors. The network is mapped by VOSviewer and shown in Figure 6. In this figure, the

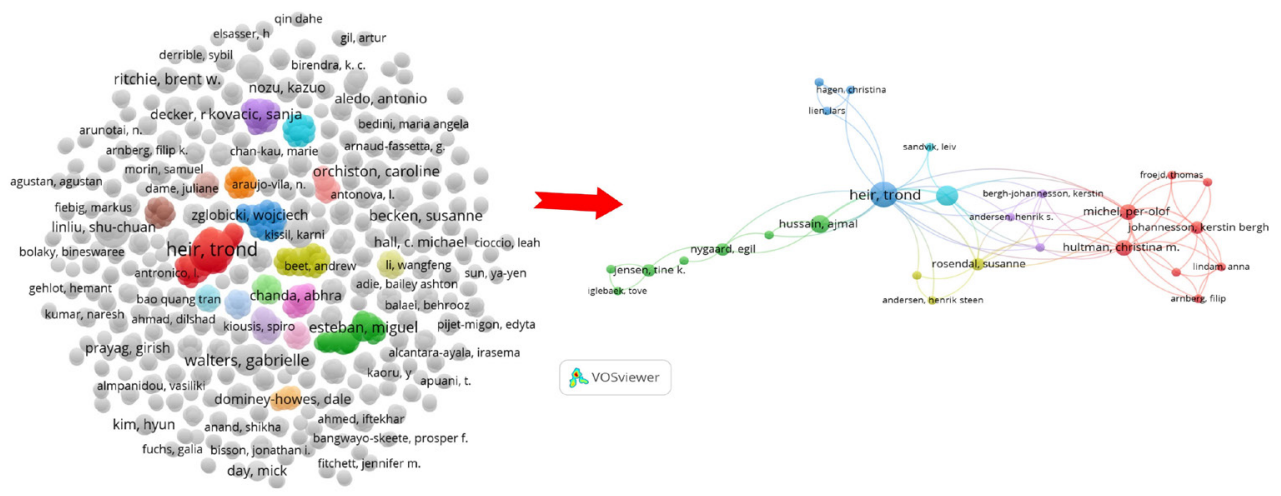

Figure 6. The author collaboration network and maximum subnetwork 
sub-figures represent the overall author collaboration network and maximum subnetwork, respectively. The overall cooperation network comprises 247 authors and 63 clusters. Among these authors, Heir Trond is the leading author both in local links and link strength, followed by Miljkovic Durda, Weisaeth Lars, and Pennington-Gray, Lori. That is to say; these authors are more collaborative with others. Moreover, in terms of a cluster, the top 10 authors are divided into 7 clusters.

\subsection{Keywords analysis}

After obtaining the general analysis and cooperation network of ND\&T, this subsection introduces the analysis of the keywords to obtain research hotspots of ND\&T. The keywords analysis is conducted from the frequency of keywords and keyword time dimension.

\subsubsection{Co-occurrence analysis}

To learn the research hotspots of the existing researches, we conduct the keywords co-occurrence of ND\&T publications. The keyword co-occurrence aims to discover two or more keywords in the same paper, which can help us identify the research hotspots (Su \& Lee, 2010). With the help of VOSviewer, the results of keywords co-occurrence can be obtained, as shown in Figure 7. The shades of color in the figure represent the number of keywords occurrences. This figure presents the 63 main keywords selected from a total of 1,123 keywords. The top five keywords are natural disasters (occurrences: 81), tourism (39), disasters (21), tsunamis (17), and climate change (16). Therefore, it can be obtained that natural disasterrelated keywords, such as tsunamis and disasters, are widely researched. Another type of hot keyword is related to tourism, such as tourism demand, sustainability.

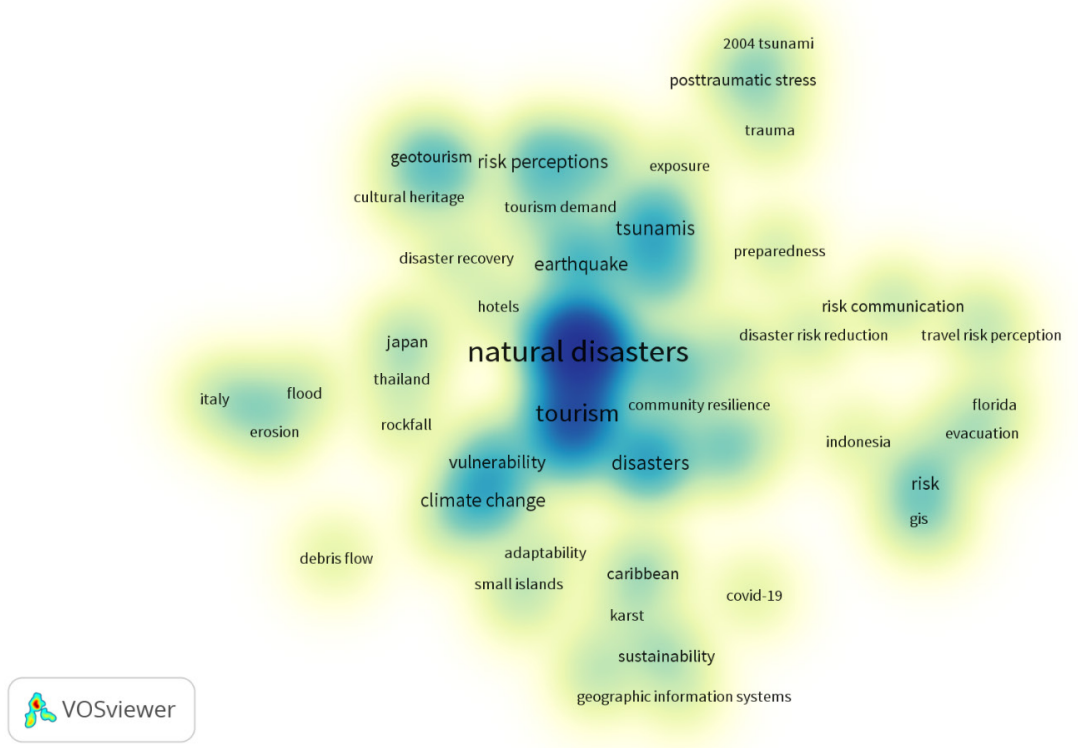

Figure 7. The main co-occurrence of keywords of all publications 


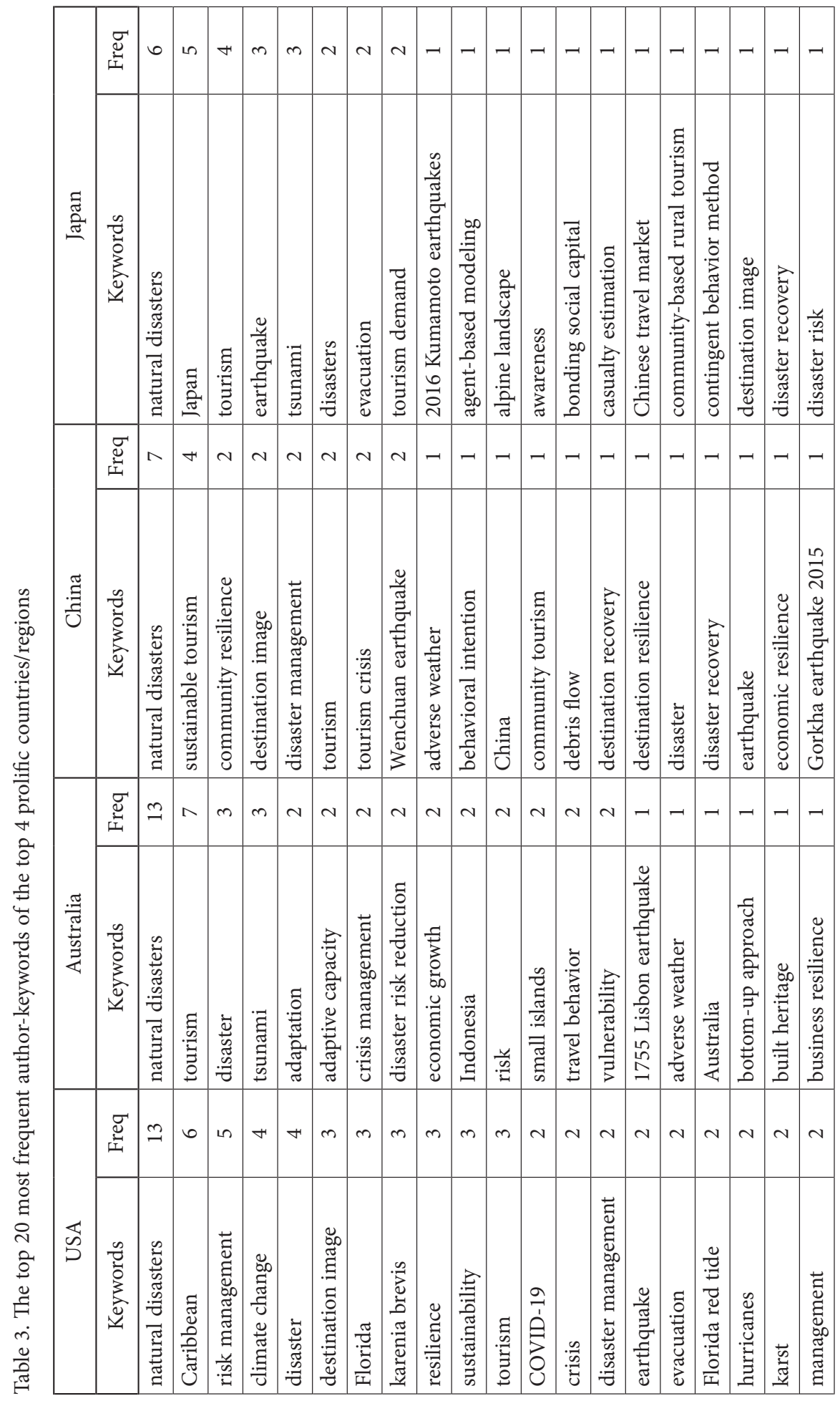


Then, to discover the research hotspots of different countries/regions, Table 3 lists the top 20 frequent keywords of the top 4 prolific countries/regions: USA, Australia, China, and Japan. From this table, it can be obtained that in each country/region, the most frequent keyword is natural disasters. Some keywords like tourism, risk, and disaster are also the focuses of researches. In addition, there are some differences between different countries/regions in terms of research focuses. For example, keywords such as Florida and hurricanes were the focuses of USA researchers, and less attention was paid to them by researchers in other countries/regions. The same thing has happened in other countries/regions, such as keywords like tiny islands in Australia, Wenchuan earthquake in China, earthquake, tsunami, and 2016 Kumamoto earthquakes in Japan. This result indicates that most researchers pay more attention to ND\&T related to their own countries/regions. In addition, China government highlights the importance of sustainable development, and therefore the frequency of keywords like sustainable tourism is relatively high. Furthermore, as an Asian country, Japanese publications also pay some attention to the Chinese travel market.

\subsubsection{Burst detection and timeline view analysis}

The co-occurrence analysis in the previous subsection provides the research hotspots of ND\&T, while how these research hotspots change over time remains to be studied. Hence, in this subsection, we introduce two mapping methods in CiteSpace to reveal this change.

First, the burst detection analysis is adopted to illustrate the focused keywords quickly and the changing of research interests. With the help of CiteSpace, the burst detection analysis results can be obtained, as shown in Table 4 . The blue line represents the time interval in this table, and it turns red if there is burstiness for the keyword. It can be found from this table that there are five burstiness keywords from 1992 to 2020, and tsunami shows the most potent bursts (strength: 4.09). The following keywords are perception (3.75), resilience (3.59), preparedness (3.56), and vulnerability (3.51). In terms of burstiness time, a tsunami is a keyword with the earliest burstiness, from 2008 to 2020.

Furthermore, keywords like resilience (2017-2020), perception (2018-2020), and preparedness (2019-2020) attract more attention in recent years. Researches focusing on these various directions can enrich innovations from the aspects of theory and application. Future researches can make improvements based on these bursting keywords.

Table 4. Top 5 keywords with the most powerful citation bursts

\begin{tabular}{|l|c|c|c|c|l|}
\hline \multicolumn{1}{|c|}{ Keywords } & Year & Strength & Begin & End & 1992-2020 \\
\hline tsunami & 1992 & 4.09 & 2008 & 2020 & \\
\hline vulnerability & 1992 & 3.51 & 2012 & 2020 & \\
\hline resilience & 1992 & 3.59 & 2017 & 2020 & \\
\hline perception & 1992 & 3.75 & 2018 & 2020 & \\
\hline preparedness & 1992 & 3.56 & 2019 & 2020 & \\
\hline
\end{tabular}


Second, the timeline view analysis is given to illustrate the trend of research hotspots in ND\&T. The timeline view analysis can be conducted in CiteSpace, and it focuses on discovering the clusters of a research topic over time. However, when adopting timeline view analysis of keywords, we find that the keywords are scattered, and as a result, many words are overlapped. Considering the relatively small number of publications before 2013, we present the timeline view of publications from 2014 to 2020 for better illustration, as shown in Figure 8 .

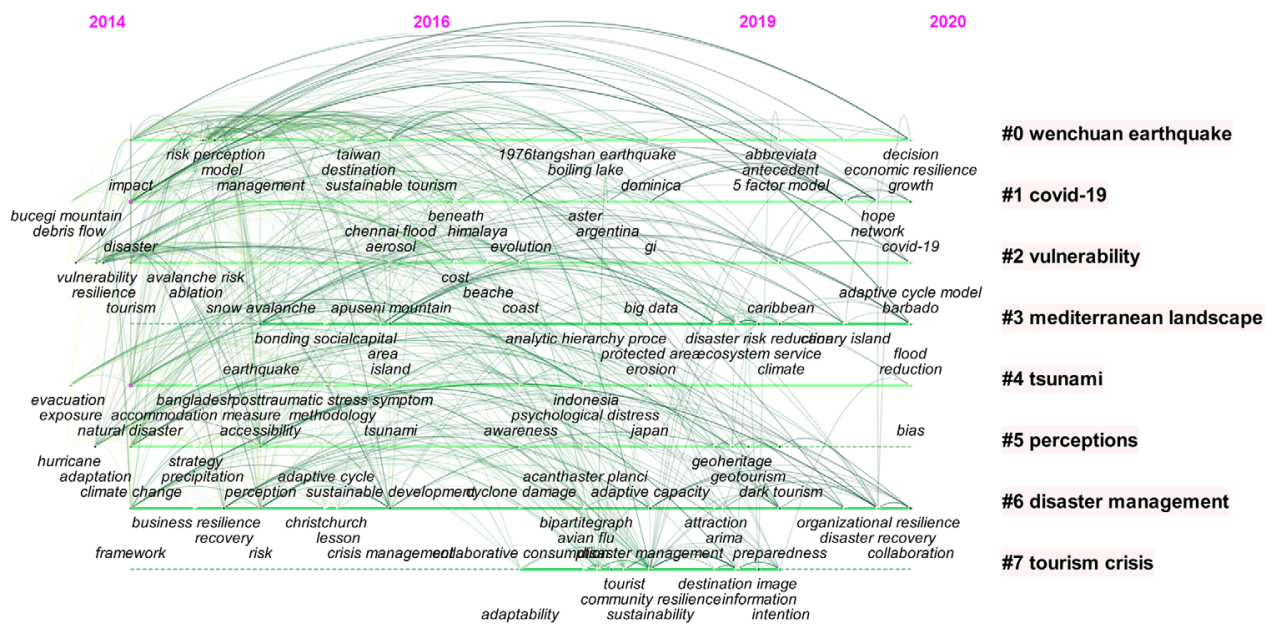

Figure 8. A timeline view of keywords in different clusters from 2014 to 2020

In this figure, there are 8 clusters, and the first three clusters are "Wenchuan earthquake", "COVID-19", and "vulnerability", with a period from 2004 to 2020. The remaining clusters with different lengths of publication time are "Mediterranean landscape", "tsunami", "perceptions", "disaster management", and "tourism crisis". As for the time of keywords, from 2014 to 2016, more attention was paid to keywords like "risk perception", "impact", "disaster", and "avalanche”. While from 2016 to 2019, keywords including "boiling lake”, "big data", "Japan”, and "disaster management" attracted more interest. And keywords such as "decision", "covid-19", "disaster recovery", "collaboration" and "network" occurred more from 2019 to 2020. In summary, the focus of researches on ND\&T between 2014 to 2020 is diverse and changes over time. Moreover, as mentioned above, research related to ND\&T is moving towards human-related keywords like perceptions, psychological distress. Besides, some recent popular keywords like big data, dark tourism, and COVID-19 are the critical branches of ND\&T. In this regard; researchers can pay further attention to the current research and grasp the future research hotspots.

Further, the overall research hotspots can be obtained by the above network. It is from this analysis that prominent research themes emerge. Detailed information on these topics and subtopics can be obtained through a literature review and discussed in the next section. 


\section{Findings and discussions}

Natural disasters such as earthquakes, tsunamis, and epidemics may have adverse effects on business management in tourism. Similarly, the business activities of the tourism industry, which involve human activities, may also lead to unexpected natural disasters. In this paper, we try to explore the relationships between ND\&T through literature review and conclude four topics as shown in Figure 9: 1) overall impact of natural disasters on business management in tourism, 2) the prevention of natural disasters to supporting business management in the tourism industry, 3 ) the revival of tourism management after a natural disaster and 4) the impact of tourism business management on natural disasters.

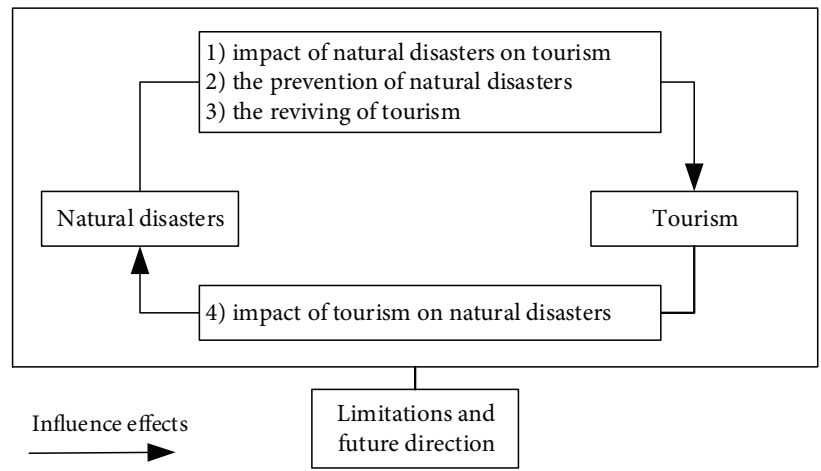

Figure 9. The framework of the theme analysis

\subsection{The overall impact of natural disasters on business management in tourism}

Tourism is a kind of service industry that depends heavily on natural resources and is vulnerable to natural disasters. In this regard, studies have discussed the impact of different natural disasters on tourists and tourist destinations.

(1) The impact of natural disasters on tourists.

Natural disasters may cause physical and psychological trauma to tourists directly or indirectly. Compared with a physical trauma that requires immediate treatment, the psychological impacts are potentially far-reaching and receive increasing attention from researchers (Huan et al., 2004). The existing researches on tourist psychology can be divided into tourist risk perception and post-disaster psychological trauma.

The analysis of tourist risk perception assists tourism operators in understanding how tourists react to risks (Valencia \& Crouch, 2008), and as a result, discover the impact of natural disasters on tourists. Some psychological factors related to tourist risk perception include personality traits, tourism worries (Kovačić et al., 2019). Researchers began to explore the relationships between natural disasters and tourists (Ruan et al., 2017). Furthermore, some researchers have confirmed that tourists with different degrees of perceived risk had various tourist satisfaction and purchase intentions (Tavitiyaman \& Qu, 2013). With the popularity of the Internet, the researcher also took the social media posts after natural disasters when analyzing tourist tourism perception and travel intention (Ai et al., 2020). Additionally, some researches focused on international travel that required more consideration of risk perception (Reisinger, 2010). 
Psychological traumas caused by natural disasters include mental health (Weiss-Dagan et al., 2018), post-traumatic stress disorder (PTSD) (Bondjers et al., 2018; Itzhaky et al., 2017). Most of the existing researchers took a long-time survey on tourists to analyze these psychological traumas. However, these surveys took lots of time and effort and often required the collaboration of multiple disciplines and departments (Hussain et al., 2011; Rosendal et al., 2014). Therefore, this kind of research is usually carried out for large-scale disaster events like a tsunami (Lindgaard et al., 2009).

(2) The impact of natural disasters on tourism destinations.

In addition to the impact on tourists, some studies have attempted to explore the dynamic impact of natural disasters on tourist destinations (Wu \& Shimizu, 2020). For example, researchers have found that natural disasters could lead to the tourism vulnerability of tourist destinations (Ak Matusin et al., 2019). Moreover, the result of exploratory research showed that large-scale disasters impacted the image of tourist destinations (Walters \& Clulow, 2010). Among these researches, a notable tourist destination, i.e., a small island, has attracted researches attention. Small islands have limited resources, are vulnerable to natural disasters, and are highly dependent on tourism (Shareef \& Hoti, 2005). Based on the characteristics of island tourism, researchers have highlighted the importance of disaster management principles to improve the resilience of small island tourism destinations to natural disasters (Filimonau \& De Coteau, 2019).

\subsection{The prevention of natural disasters to supporting business management in the tourism industry}

The prevention of natural disasters is highly valued because natural disasters are uncertain and often inevitable. Therefore, many studies attempt to find effective prevention methods to support business management in the tourism industry (Tsai \& Chen, 2011), including assessing and managing risk and discussing disaster prevention measures.

The risk assessment of unexpected natural disasters can provide the basis for policymakers and tourism operators to make risk emergency strategies and tourism planning (Shareef \& McAleer, 2008). Furthermore, some researchers developed a tourism risk evaluation platform to help government departments and the tourism industry respond rapidly to natural disasters (Tsai, 2017). In addition to risk assessment, some researchers highlighted the necessity of risk management in the tourism industry. The frequency and inevitability of natural disasters make it increasingly urgent to take preventive measures for sustainable tourism (Williams \& Ponsford, 2009). Some of the existing research highlighted the necessity of unusual events explanation and disaster information disclosure to the local population and tourists. This is because public information about possible consequences due to natural disasters can lead to more precautionary behavior (Mara \& Vlad, 2008). Especially in natural disasters involving supraglacial flooding and ice collapse, the explanation is necessary to prevent natural disasters from affecting tourism (Goodsell et al., 2005). For another, some researchers proposed disaster prediction methods by analyzing the susceptibility of natural disasters to prevent natural disasters (Frattini et al., 2008). 


\subsection{The revival of tourism management after a natural disaster}

In addition to disaster prevention, rebuilding tourism after natural disasters is also been the focus of research in recent years (Cioccio \& Michael, 2007). According to the two subjects related to tourism reconstruction, namely, the government departments and tourism stakeholders like tourism operators, the existing research on tourism revival can be summarized into 1) policy suggestions related to government departments, and 2) natural disasters analysis and planning to tourism stakeholders.

Tourism policy-making after natural disasters aims at the sustainable development of the tourism industry. Analysis of natural disasters' impact will reference policy-making (Tsai et al., 2011). In terms of the mountain risk caused by natural disasters, some researchers suggested that governments should conduct policy adaptation for the tourism sector and system to improve the resilience of the tourism (Kariya et al., 2007; Klint et al., 2012). Also, some researches informed policy-making and strategic planning (Ruhanen et al., 2012; Sheller, 2020). In order to develop eco-friendly tourism activities, Jangra and Kaushik (2020) focused on the impact of unregulated tourism, and therefore the intervention policies could be made.

Unlike policy suggestions that focus on providing reference information to government departments, natural disaster analysis and planning related to tourism stakeholders pay attention to putting forward disaster management methods and tourism revival measures (Chan et al., 2020). Furthermore, some researchers related to natural disaster analysis and planning emphasized the importance of disaster prevention activities (Kim, 2014), disaster management collaboration with local governments (Nguyen et al., 2018), and the role of social media (Möller et al., 2018). In addition, some researchers suggested that the tourism reviving measures should consider disaster management (Orchiston, 2012). In addition, some researches focused on providing some marketing implications for tourism operators (Amujo \& Otubanjo, 2012; Walters et al., 2014).

\subsection{The impact of tourism on natural disasters}

Few studies are focusing on the impact of tourism on natural disasters. Therefore, based on the literature review, we divide the existing researches into 1) impact of tourism development on natural disasters and 2) interaction impact between natural disasters and tourism.

The development of tourism may lead to natural disasters in some regions (Baumann \& Kaiser, 1999). Under the influence of tourism activities, the increased possibility of human existence will lead to a greater risk of natural disasters (Keiler, 2004). In addition, influenced by the expansion of settlements in the Alps due to tourism, Singer et al. (2009) discovered an increasing conflict between land use and natural disaster prevention. Moreover, according to a survey, the growing tourism impacted shorelines and the sea over time (Mosley, 2014). Furthermore, the increase in tourism has resulted in other natural disasters like the risk of avalanches (Decker et al., 2003; Rice Jr et al., 2000) and the outbreak of pandemics (S. M. Wang et al., 2001).

The influence between natural disasters and tourism is interactive, and some researchers, therefore, focused on the interaction analysis between ND\&T (Nakamura et al., 2020). At 
the same time, natural disasters may occur more frequently because the increase of tourism infrastructure can exceed the environment's carrying capacity. Bang Vu et al. (2017) investigated the relationship between cyclone activity and tourism, and results show that there were feedback effects between cyclones and unsustainable tourism. In other words, the cyclone damage reduced the number of tourist arrivals, and some unsustainable activities by the tourism industry increased the cyclone damage.

\subsection{Limitations and directions for future research}

Based on the above research topics, the subsection discusses some limitations and directions for future research:

First, although the different natural disasters have been studied in the existing research, impacts of some unfrequent and far-reaching natural disasters like the COVID-19 epidemic remain to be analyzed. Second, the characters of COVID-19 are different from other natural disasters; thus, the impacts of COVID-19 on tourism business management in a different epidemic stage are worth future research.

Second, in terms of tourist psychological analysis, most of the researches focus on disaster-stricken tourists and less on potential tourists who are not affected by natural disasters. However, the analysis of these potential tourists can reference tourism recovery from a new perspective. Future researches, therefore, should focus on the balance of these two types of tourists to attract more potential tourists.

Third, in terms of natural prevention measures, the existing research mainly focuses on qualitative analysis like disclosing disaster information in time. However, the prosperity of artificial intelligence technology offers the promise of alternative means to obtain an accurate prediction of natural disasters. Therefore, future research should combine knowledge from other disciplines to propose effective natural disaster prediction methods to promote the sustainable development of business management in the tourism industry.

Fourth, in terms of tourism revival measures, most of the existing studies analyze the policy suggestions and disaster management, and few studies took the psychological factors of tourists into account. However, the psychological analysis of tourists on tourism recovery is helpful to find out the key factors that affect tourists to purchase again. Based on this, some effective tourism revival measures can be put forward to stimulate consumption. Especially in the current post-epidemic, the demand of the tourism market is vast, so overcoming the psychological barriers of tourists and promoting tourists' consumption is worth further study.

Furthermore, finally, as we mentioned above, relatively few studies focus on the impact of tourism on natural disasters. However, human tourism activities have affected natural scenic spots and may even lead to natural disasters. Therefore, the research related to the impact of tourism on natural disasters should be highlighted in the future.

\section{Conclusions}

To explore the research status and future direction of ND\&T, this paper summarizes the general trend of current research in terms of publication time and research direction. Based on VOSviewer and CiteSpace, this paper selects the representative data to analyze literature 
on ND\&T from four perspectives: first, general analysis is conducted by statistics analysis on some prolific features of publications. The analysis results indicate that ND\&T has attracted the attention of scholars in many research fields. Second, the cooperation network analysis is adopted to reveal the co-relations between publications. From the analyses, it can be found that the cooperation between these publication sources is not very close, but the co-citation relationship between authors is much closer. Then, the analysis of the keywords is conducted to obtain research hotspots of ND\&T. The results suggest that the focuses of research on ND\&T are diverse and change over time and move toward human-related keywords. Finally, the main topics of the existing researches are obtained by literature review and concluded as: 1) overall impact of natural disasters on business management in tourism, 2) the prevention of natural disasters to supporting business management in the tourism industry, 3) the revival of tourism management after the natural disaster and 4) the impact of tourism business management on natural disasters. Based on the concluded topics, limitations and directions for future research are also discussed in this paper.

The analysis of general developments and cooperation relationships of the existing publications can help researchers better understand the structure and the development process of ND\&T. Additionally, the findings in this paper provide the critical values to reference for researchers, and therefore make it more accessible to them. In the future, researchers can focus on the possible future research directions of ND\&T to further deepen the research in this field.

\section{Acknowledgements}

This work was supported by the National Natural Science Foundation of China (Nos. 71571123 and 71771155).

\section{Author contributions}

Shuixia Chen was responsible for data collection and wrote the first draft of the article. Zeshui $\mathrm{Xu}$ revised the first draft of the article and was responsible for supervision. Xinxin Wang revised the first draft of the article. Marinko Škare conceived the study and revised the first draft of the article.

\section{Disclosure statement}

No potential conflict of interest was reported by the author(s).

\section{References}

Ai, J., Lv, X., \& Gursoy, D. (2020). Impact of social media posts on travelers' attitudes and behaviors towards a destination after a natural disaster: moderating role of the source of the post. Journal of Sustainable Tourism. https://doi.org/10.1080/09669582.2020.1831002

Ak Matusin, A. M. R., Chamhuri, S., \& Halim, S. (2019). Vulnerability framework of tourism to natural disasters. Malaysian Journal of Society and Space, 15(4), 137-150.

https://doi.org/10.17576/geo-2019-1504-10 
Amujo, O., \& Otubanjo, O. (2012). Leveraging rebranding of 'unattractive' nation brands to stimulate post-disaster tourism. Tourist Studies, 12(1), 87-105. https://doi.org/10.1177/1468797612444196

Bang Vu, T., Iksoon Im, E., Thompson, R. R., \& DeWitt, T. (2017). The interaction of tourism and cyclone activity in East Asia: Sustainability and disasters. Tourism Review International, 21(4), 379-393. https://doi.org/10.3727/154427217X15094520591358

Baumann, F., \& Kaiser, K. F. (1999). The Multetta debris fan, eastern Swiss Alps: A 500-year debris flow chronology. Arctic, Antarctic, and Alpine Research, 31(2), 128-134. https://doi.org/10.1080/15230430.1999.12003290

Bondjers, K., Willebrand, M., \& Arnberg, F. (2018). Similarity in symptom patterns of posttraumatic stress among disaster-survivors: A three-step latent profile analysis. European Journal of Psychotraumatology, 9(1), 1546083. https://doi.org/10.1080/20008198.2018.1546083

Chan, C. S., Nozu, K., \& Cheung, L. (2020). Tourism and natural disaster management process: Perception of tourism stakeholders in the case of Kumamoto earthquake in Japan. Current Issues in Tourism, 23(15), 1864-1885. https://doi.org/10.1080/13683500.2019.1666809

Cioccio, L., \& Michael, E. (2007). Hazard or disaster: Tourism management for the inevitable in Northeast Victoria. Tourism Management, 28(1), 1-11. https://doi.org/10.1016/j.tourman.2005.07.015

Cobo, M. J., López-Herrera, A. G., Herrera-Viedma, E., \& Herrera, F. (2014). Science mapping software tools: Review, analysis, and cooperative study among tools. Journal of the American Society for Information Science \& Technology, 62(7), 1382-1402. https://doi.org/10.1002/asi.21525

Decker, R., Rice Jr, R., Putnam, S., \& Singer, S. (2003). Rural intelligent transportation system natural-hazard management on low-volume roads. Transportation Research Record, 1819(1), 255-259. https://doi.org/10.3141/1819a-37

Filimonau, V., \& De Coteau, D. (2019). Tourism resilience in the context of integrated destination and disaster management (DM2). International Journal of Tourism Research, 22(2), 202-222. https://doi.org/10.1002/jtr.2329

Frattini, P., Crosta, G., Carrara, A., \& Agliardi, F. (2008). Assessment of rockfall susceptibility by integrating statistical and physically-based approaches. Geomorphology, 94(3-4), 419-437. https://doi.org/10.1016/j.geomorph.2006.10.037

Goodsell, B., Anderson, B., Lawson, W., \& Owens, I. (2005). Outburst flooding at Franz Josef Glacier, South Westland, New Zealand. New Zealand Journal of Geology and Geophysics, 48(1), 95-104. https://doi.org/10.1080/00288306.2005.9515101

Huan, T. C., Beaman, J., \& Shelby, L. (2004). No-escape natural disaster: Mitigating impacts on tourism. Annals of Tourism Research, 31(2), 255-273. https://doi.org/10.1016/j.annals.2003.10.003

Hussain, A., Weisæth, L., \& Heir, T. (2011). Psychiatric disorders and functional impairment among disaster victims after exposure to a natural disaster: A population based study. Journal of Affective Disorders, 128(1-2), 135-141. https://doi.org/10.1016/j.jad.2010.06.018

Itzhaky, H., Weiss-Dagan, S., \& Taubman-Ben-Ari, O. (2017). Internal and community recourses' contribution to level of posttraumatic symptoms-the case of tourists after the earthquake in Nepal, 2015. Psychological Trauma: Theory, Research, Practice, and Policy, 10(2), 239. https://doi.org/10.1037/tra0000280

Jangra, R., \& Kaushik, S. (2020). Understanding tribal community's perception toward tourism impacts: The case of emerging destinations in western Himalaya, Kinnaur. Asian Geographer, 37, 1-24. https://doi.org/10.1080/10225706.2020.1830134

Jiang, Y., Ritchie, B. W., \& Benckendorff, P. (2019). Bibliometric visualisation: An application in tourism crisis and disaster management research. Current Issues in Tourism, 22(16), 1925-1957. https://doi.org/10.1080/13683500.2017.1408574

Johnson, A. G., \& Samakovlis, I. (2019). A bibliometric analysis of knowledge development in smart tourism research. Journal of Hospitality and Tourism Technology, 10(4), 600-623.

https://doi.org/10.1108/JHTT-07-2018-0065 
Kariya, Y., Sato, G., Mokudai, K., Komori, J., Ishii, M., Nishii, R., Miyazawa, Y., \& Tsumura, N. (2007). Rockfall hazard in the Daisekkei Valley, the northern Japanese Alps, on 11 August 2005. Landslides, 4(1), 91-94. https://doi.org/10.1007/s10346-006-0067-7

Keiler, M. (2004). Development of the damage potential resulting from avalanche risk in the period 1950-2000, case study Galtür. Natural Hazards and Earth System Science, 4(2), 249-256. https://doi.org/10.5194/nhess-4-249-2004

Kim, H. (2014). Hurricane impacts on southeastern United States coastal national park visitation. Tourism Geographies, 16(3), 364-381. https://doi.org/10.1080/14616688.2013.823235

Klint, L., Wong, E., Jiang, M., DeLacy, T., Harrison, D., \& Dominey-Howes, D., (2012). Climate change adaptation in the Pacific Island tourism sector: Analysing the policy environment in Vanuatu. Current Issues in Tourism, 15(3), 247-274. https://doi.org/10.1080/13683500.2011.608841

Kovačić, S., Jovanovic, T., Miljković, Đ., Lukic, T., Markovic, S., Vasiljevic, D., Vujicic, M., \& Ivkov, M. (2019). Are Serbian tourists worried? The effect of psychological factors on tourists' behavior based on the perceived risk. Open Geosciences, 11(1), 273-287. https://doi.org/10.1515/geo-2019-0022

Lindgaard, C., Iglebaek, T., \& Jensen, T. (2009). Changes in family functioning in the aftermath of a natural disaster: The 2004 Tsunami in Southeast Asia. Journal of Loss \& Trauma, 14(2), 101-116. https://doi.org/10.1080/15325020802537138

Mara, S., \& Vlad, S. (2008). Positive effects of natural hazards on cultural heritage in Romania. Geografia Fisica e Dinamica Quaternaria, 31, 181-186.

Möller, C., Wang, J., \& Nguyen, H., (2018). Strongerthanwinston: Tourism and crisis communication through Facebook following tropical cyclones in Fiji. Tourism Management, 69, 272-284. https://doi.org/10.1016/j.tourman.2018.05.014

Mosley, S. (2014). Coastal cities and environmental change. Environment and History, 20(4), 517-533. https://doi.org/10.3197/096734014X14091313617280

Moyle, B., Moyle, C.-1., Ruhanen, L., Weaver, D., \& Hadinejad, A. (2021). Are we really progressing sustainable tourism research? A bibliometric analysis. Journal of Sustainable Tourism, 29(1), 106-122. https://doi.org/10.1080/09669582.2020.1817048

Nakamura, S., Ono, S., \& Kawasaki, H., (2020). Flooded road detection from driving recorder: Training deep net for rare event using GANs semantic information. International Journal of Intelligent Transportation Systems Research, 19, 1-11. https://doi.org/10.1007/s13177-019-00219-9

Nguyen, D., Imamura, F., \& Iuchi, K. (2018). Barriers towards hotel disaster preparedness: Case studies of post 2011 Tsunami, Japan. International Journal of Disaster Risk Reduction, 28, 585-594. https://doi.org/10.1016/j.ijdrr.2018.01.008

Orchiston, C. (2012). Seismic risk scenario planning and sustainable tourism management: Christchurch and the Alpine Fault zone, South Island, New Zealand. Journal of Sustainable Tourism, 20(1), 59-79. https://doi.org/10.1080/09669582.2011.617827

Rabinovich, A. B., Thomson, R. E., \& Stephenson, F. E. (2006). The Sumatra tsunami of 26 December 2004 as observed in the North Pacific and North Atlantic oceans. Surveys in Geophysics, 27(6), 647-677. https://doi.org/10.1007/s10712-006-9000-9

Reisinger, Y. (2010). Differences in the perceived influence of natural disasters and travel risk on international travel. Tourism Geographies, 12(1), 1-24. https://doi.org/10.1080/14616680903493621

Rice Jr, R., Decker, R., Jensen, N., Patterson, R., \& Singer, S. (2000). Rural intelligent transportation system for snow avalanche detection and warning. Transportation Research Record, 1700(1), 17-23. https://doi.org/10.3141/1700-04

Rodríguez-López, M. E., Alcántara-Pilar, J. M., Del Barrio-Garcia, S., \& Munoz-Leiva, F. (2020). A review of restaurant research in the last two decades: A bibliometric analysis. International Journal of Hospitality Management, 87, 102387. https://doi.org/10.1016/j.ijhm.2019.102387 
Rosendal, S., Mortensen, E., Andersen, H., \& Heir, T. (2014). Use of Health care services before and after a natural disaster among survivors with and without PTSD. Psychiatric Services, 65(1), 91-97. https://doi.org/10.1176/appi.ps.201200535

Ruan, W. Q., Li, Y. Q., \& Liu, C. H. (2017). Measuring Tourism risk impacts on destination image. Sustainability, 9(9), 1501. https://doi.org/10.3390/su9091501

Ruhanen, L., Moyle, C. L., \& Moyle, B. (2012). Strategic issues in the Australian tourism industry: A 10-year analysis of national strategies and plans. Asia Pacific Journal of Tourism Research, 18(3), 220-240. https://doi.org/10.1080/10941665.2011.640701

Shareef, R., \& Hoti, S. (2005). Small island tourism economies and country risk ratings. Mathematics and Computers in Simulation, 68(5-6), 553-566. https://doi.org/10.1016/j.matcom.2005.02.012

Shareef, R., \& McAleer, M. (2008). Modelling international tourism demand and uncertainty in Maldives and Seychelles: A portfolio approach. Mathematics and Computers in Simulation, 78(2-3), 459-468. https://doi.org/10.1016/j.matcom.2008.01.025

Sheller, M. (2020). Reconstructing tourism in the Caribbean: Connecting pandemic recovery, climate resilience and sustainable tourism through mobility justice. Journal of Sustainable Tourism, 29(9), 1436-1449. https://doi.org/10.1080/09669582.2020.1791141

Singer, J., Schuhbäck, S., Wasmeier, P., Thuro, K., Heunecke, O., Wunderlich, T., \& Festl, J. (2009). Monitoring the aggenalm landslide using economic deformation measurement techniques. Austrian Journal of Earth Sciences, 102(2), 20-34.

Stylidis, D., Biran, A., Sit, J., \& Szivas, E. M. (2014). Residents' support for tourism development: The role of residents' place image and perceived tourism impacts. Tourism Management, 45, 260-274. https://doi.org/10.1016/j.tourman.2014.05.006

Su, H. N., \& Lee, P. C. (2010). Mapping knowledge structure by keyword co-occurrence: A first look at journal papers in Technology Foresight. Scientometrics, 85(1), 65-79. https://doi.org/10.1007/s11192-010-0259-8

Tavitiyaman, P., \& Qu, H. (2013). Destination image and behavior intention of travelers to Thailand: The moderating effect of perceived risk. Journal of Travel \& Tourism Marketing, 30(3), 169-185. https://doi.org/10.1080/10548408.2013.774911

Tsai, C. H., Wu, T. C., Wall, G., \& Linliu, S. C. (2016). Perceptions of tourism impacts and community resilience to natural disasters. Tourism Geographies, 18(2), 152-173. https://doi.org/10.1080/14616688.2016.1149875

Tsai, C. (2017). Web-based tourism risk assessment system incorporating Web-GIS and HIP technologies. International Journal of Computer Applications in Technology, 55(2), 128-137. https://doi.org/10.1504/IJCAT.2017.082867

Tsai, C. H., \& Chen, C. W. (2011). The establishment of a rapid natural disaster risk assessment model for the tourism industry. Tourism Management, 32(1), 158-171. https://doi.org/10.1016/j.tourman.2010.05.015

Tsai, H.-T., Tseng, C.-J., Tzeng, S.-Y., Wu, T.-J., \& Day, J.-d. (2011). The impacts of natural hazards on Taiwan's tourism industry. Natural Hazards, 62(1), 83-91. https://doi.org/10.1007/s11069-011-0034-z

Valencia, J., \& Crouch, G. (2008). Travel behavior in troubled times: The role of consumer self-confidence. Journal of Travel \& Tourism Marketing, 25(1), 25-42. https://doi.org/10.1080/10548400802164871

Verma, S., \& Gustafsson, A. (2020). Investigating the emerging COVID-19 research trends in the field of business and management: A bibliometric analysis approach. Journal of Business Research, 118, 253-261. https://doi.org/10.1016/j.jbusres.2020.06.057

Walters, G., \& Clulow, V. (2010). The tourism market's response to the 2009 black saturday bushfires: The case of Gippsland. Journal of Travel \& Tourism Marketing, 27(8), 844-857.

https://doi.org/10.1080/10548408.2010.527250 
Walters, G., Mair, J., \& Ritchie, B. (2014). Understanding the tourist's response to natural disasters: The case of the 2011 Queensland floods. Journal of Vacation Marketing, 21(1), 101-113. https://doi.org/10.1177/1356766714528933

Wang, S. M., Liu, C. C., Huang, Y. S., Yang, Y. J., \& Lei, H. Y. (2001). Change in hepatitis A virus seroepidemiology in southern Taiwan: A large percentage of the population lack protective antibody. Journal of Medical Virology, 64(2), 104-108. https://doi.org/10.1002/jmv.1024

Wang, X. X., Chang, Y., Xu, Z. S., Wang, Z., \& Kadirkamanathan, V. (2021a). 50 Years of international journal of systems science: A review of the past and trends for the future. International Journal of Systems Science, 52(8), 1515-1538. https://doi.org/10.1080/00207721.2020.1862937

Wang, X. X., Xu, Z. S., Qin, Y., \& Skare, M. (2021b). Service networks for sustainable business: A dynamic evolution analysis over half a century. Journal of Business Research, 136, 543-557. https://doi.org/10.1016/j.jbusres.2021.07.062

Weiss-Dagan, S., Itzhaky, H., \& Taubman-Ben-Ari, O. (2018). Backpackers in the Nepal 2015 earthquake: The contribution of personal and social resources to mental health. Journal of Community Psychology, 46(6), 689-700. https://doi.org/10.1002/jcop.21966

Williams, P., \& Ponsford, I. (2009). Confronting tourism's environmental paradox: Transitioning for sustainable tourism. Futures, 41(6), 396-404. https://doi.org/10.1016/j.futures.2008.11.019

Wu, L., \& Shimizu, T. (2020). Analyzing dynamic change of tourism destination image under the occurrence of a natural disaster: Evidence from Japan. Current Issues in Tourism, 23(16), 2042-2058. https://doi.org/10.1080/13683500.2020.1747993

Yu, D. J., Xu, Z .S., Pedrycz, W., \& Wang, W. (2017). Information Sciences 1968-2016: A retrospective analysis with text mining and bibliometric. Information Sciences, 418, 619-634. https://doi.org/10.1016/j.ins.2017.08.031

Zhou, L., Wu, X. H., Xu, Z. S., \& Fujita, H. (2018). Emergency decision making for natural disasters: An overview. International Journal of Disaster Risk Reduction, 27, 567-576. https://doi.org/10.1016/j.ijdrr.2017.09.037 